\title{
Influence of Different Concentrations of Surfactants on Dissolution Profiles of Extemporaneously Compounded Pessaries with Clindamycin Phosphate
}

\author{
Vesna Savić1 ${ }^{*}$, Ivana Nešić1, Milica Martinović ${ }^{1}$, Ana Markovićc ${ }^{1}$, and Ivana Gajić ${ }^{2}$ \\ ${ }^{1}$ Department of Pharmacy, Faculty of Medicine, University of Niš, Niš, Republic of Serbia. \\ ${ }^{2}$ Faculty of Technology, University of Niš, Leskovac, Republic of Serbia.
}

e-mail:vesna.savic@medfak.ni.ac.rs, vsavic203@yahoo.com

\begin{abstract}
Three groups of pessaries with clindamycin phosphate as the active substance, and with different concentrations of polysorbate 80 as a surfactant incorporated in the glycerol-gelatin base, were prepared simultaneously. Potential differences in their dissolution profiles and bioavailability were examined, i.e., the influence of surfactant on the release of the active substance. Taking into account the difference and similarity factors, there were little differences in dissolution rates among the tested groups of pessaries with different surfactant concentrations. Therefore, although the surfactant may help to release the drug, it should be used in the appropriate concentration. The prepared pessaries were also tested for uniformity of mass and active substance content. The results showed that the tested pessaries met the pharmacopoeial requirements. This paper focuses on extemporaneously compounded pessaries, because extemporaneously compounded drugs are preparations mostly used for personalized therapy or during drug deficits. However, there are few regulations concerning this type of drug and the content of active substance in them is not monitored. The dissolution test is a method that could potentially be used for auditing extemporaneously compounded pessaries.
\end{abstract}

KEYWORDS: Clindamycin phosphate, pessaries, extemporaneous compounding, dissolution test

\section{INTRODUCTION}

he production of pharmaceutical extemporaneous preparations, which are issued immediately after the formulation, provide individualization of therapy, as well as the possibility of choosing the most suitable substrate for the appropriate active substance, which also affects efficacy of the drug. The content of the active substance in extemporaneously compounded preparations is not subject to control or verification in everyday pharmacy practice. However, by validating the technological process of production and quality of the obtained preparations, the selection of substrates for extemporaneously compounded preparations can be optimized. That way, guidelines for the production of extemporaneously compounded preparations or galenic formulations, including vaginal preparations, could be developed to ensure optimal therapeutic efficacy $(1,2)$.

Vaginal preparations contain one or more active substances and are intended for vaginal application to achieve a local effect. They can be liquid, semi-solid, or solid (3). Ideal vaginal preparations should be safe, easy, and painless to use, especially because most of them are designed and intended for self-administration. Also, they should be characterized with high bioavailability and acceptability in terms of economy and affordability (4). The most common type of vaginal preparations are pessaries that consist of the active substance dispersed or dissolved in a hydrophilic or lipophilic base. The base can be dissolved in water and body fluids or can be melted in contact with body temperature (3). A glycerol-gelatin base for pessaries is hydrophilic and dissolves in vaginal fluid, but its dissolution rate depends on the ratio of glycerol and gelatin used. Gelatin can exist in two states and switch between them - solid state (at $80^{\circ} \mathrm{C}$ ) and gel state (at lower temperatures). As a polypeptide, it creates 3D networks with glycerol and water (4).

When formulating pessaries, some additives need to be incorporated. According to the International Pharmaceutical Excipients Council (IPEC), an excipient is any substance that is not a drug or a precursor of a drug and is safe to use. Excipients, which are officinal according to the pharmacopeias of the USA, Europe, and Japan are considered acceptable (5). Surfactants are added to achieve emulsification of liquid components by improved

* Corresponding author. 
wetting of the dispersed particles, which consequently leads to better releasing and spreadability of the active substance (6).

Within the general monographs of vaginal preparations in European Pharmacopoeia 9.0 (EP), as well as in Yugoslav Pharmacopoeia 2000, the following tests are prescribed: uniformity of dosage units, uniformity of content, uniformity of mass, and dissolution test, and for pessaries, vaginal tablets and vaginal capsules disintegration should also be examined $(3,7)$. From the pharmaceutical, technological, and biopharmaceutical aspects, the rate of dissolution of the active substance from dosage forms is of particular importance. Testing the dissolution rate of a drug substance from medicinal preparations is a useful tool for evaluating drug preparation during the formulation development phase for quality control and for testing the stability of the preparation $(8,9)$. In addition to showing whether the dissolution rate of the active substance is in accordance with the pharmacopoeia requirements, this assay aims to predict the dissolution rate of the active substance from the drug in the body after its application in vivo $(10,11)$.

The dissolution test for solid dosage forms is usually performed using a United States Pharmacopeia (USP) dissolution test apparatus II (paddles). This device consists of a glass vessel with a working volume of $900 \mathrm{~mL}$ and an agitation system - a two-blade paddle impeller that rotates in the center of the vessel $(3,12)$. The amount of active substance dissolved in the dissolution medium after the prescribed time is expressed as a percentage of drug released and is measured from samples taken after certain time intervals from the medium in the glass vessel (3).

The vagina, as the unique organ characterized with epithelium containing specific vaginal flora, vaginal secretions, and $\mathrm{pH}$ (in healthy women it should be 4-5), serves as a favorable place for local and sometimes systemic delivery of drugs, considering female reproductive conditions (13). Bacterial vaginosis is the most common vaginal condition in women; in a study conducted in the Republic of Serbia, bacterial vaginosis was diagnosed in $25 \%$ of tested women, while in the US it is estimated that its prevalence is $29.2 \%$ ( 21.2 million) among reproductively capable women (19-49 years old) (14-16). The recommended regimen for the treatment of bacterial vaginosis includes clindamycin as one drugs of choice, applied in a dose of $100 \mathrm{mg}$ intravaginally in the form of a pessary or vaginal cream for 3-7 days (17-19). Clindamycin, a lincomycin derivative introduced in 1966, is an important antibiotic active against G-positive aerobes and anaerobes (20-23). It binds to the bacterial 505 ribosomal subunit and, as a result, acts bacteriostatically by inhibition of bacterial protein synthesis $(24,25)$.

The development of a methodology for testing the dissolution rate is often the task of the manufacturer or the appropriate institution that evaluates the preparation. The aim of this study was to examine potential differences in the dissolution profiles and bioavailability of clindamycin phosphate pessaries containing different concentrations of nonionic surfactant (polysorbate 80), i.e., to examine whether the presence of a surfactant may affect the release of the active substance. Glycerolbased hydrophilic pessaries were compounded, tested for uniformity of mass and active substance content, and dissolution profiles were analyzed using USP apparatus 2 and high-performance liquid chromatography (HPLC) as an analytical method for determination of released clindamycin phosphate in dissolution medium over time.

\section{METHODS}

\section{Reagents}

Clindamycin phosphate, gelatin, and glycerol (Sigma Aldrich, Darmstadt, Germany), Tween 80 (polysorbate 80) (Fagron Hellas, Trikala-Larisa, Greece), and liquid paraffin (Fagron Hellas) were used for the preparation of pessaries. For making vaginal fluid simulant, the following reagents were used: sodium chloride, potassium hydroxide, albumin solution (Superlab, Belgrade, Serbia), calcium hydroxide, lactic acid, acetic acid, urea, glucose (Centrohem, Stara Pazova, Serbia), and purified water.

\section{Preparation of Studied Pessaries}

Three groups of 20 pessaries were made with surfactant concentrations of $4 \%, 5 \%$, and $6 \%$ for group $A, B$, and C, respectively. Each pessary contained $120 \mathrm{mg}$ of clindamycin phosphate. The ratio of glycerol, gelatin, and water in the base was 6:1:2 w/w/w. The appropriate amount of gelatin was left to swell for 15 minutes in the prescribed amount of water, after which the mixture was dissolved by heating in a water bath (Table 1). Glycerol heated to the same temperature was added. The dissolved medium was gradually added to a porcelain mortar with clindamycin phosphate and surfactant. The base was carefully mixed until homogenized, after which warm water was added to the prescribed mass. Finally, the mass was poured into a 2-g plastic mold. As the displacement value of glycerol-gelatin base is 1.3, 2.6 grams of this base can fit in 2-g molds.

\section{Uniformity of Mass}

According to $E P$, twenty randomly selected pessaries were individually weighed and the average mass was 


Table 1. Formulations of Studied Glycerol-Gelatin Based Pessaries with Clindamycin Phosphate
\begin{tabular}{|c|c|c|c|}
\hline \multirow{2}{*}{ Substance } & \multicolumn{3}{|c|}{ Mass of Substances (g) } \\
\cline { 2 - 4 } & A (4\% Polysorbate 80) & B (5\% Polysorbate 80) & C (6\% Polysorbate 80) \\
\hline Clindamycin phosphate & 2.88 & 2.88 & 2.88 \\
\hline Glycerol & 37.44 & 37.44 & 37.44 \\
\hline Gelatin & 6.24 & 6.24 & 6.24 \\
\hline Polysorbate 80 & 2.50 & 3.12 & 3.74 \\
\hline Purified water & 13.34 & 12.72 & 12.10 \\
\hline Total & 62.40 & 62.40 & 62.40 \\
\hline
\end{tabular}

calculated (3). Not more than two pessaries can have mass that deviates from the average mass more than $5 \%$, and none should deviate more than $10 \%$ (3).

\section{Uniformity of Content}

As stated in $E P$, the dosage form meets the requirements if the individual content of the active substance (clindamycin phosphate) in randomly taken 10 dosage units is within the range of $75-125 \%$ of the average content (3). Not more than one individual content shall be outside the range of $85-115 \%$ of the average content (3). For this purpose, HPLC was used.

\section{Preparation of Tested Samples for HPLC analysis}

The sample (concentration of $80 \mu \mathrm{g} / \mathrm{mL}$ ) was prepared by dissolving one pessary in $50 \mathrm{~mL}$ of phosphate buffer (pH 2.5). The amount of obtained solution corresponding to the content of $2 \mathrm{mg}$ of active substance $(0.83 \mathrm{~mL})$ was then taken into a normal vessel $(25 \mathrm{~mL})$ and filled with phosphate buffer ( $\mathrm{pH} 2.5)$. The basic standard solution of the active substance was made at a concentration of 1000 $\mu \mathrm{g} / \mathrm{mL}$ by dissolving $10 \mathrm{mg}$ of clindamycin phosphate in phosphate buffer $(\mathrm{pH} 2.5)$. This solution was later used for making the working standards $(40,60,80,100$, and $120 \mu \mathrm{g} / \mathrm{mL}$ ) needed to obtain the reference standard curve (26).

\section{HPLC Analysis}

The HPLC analysis was performed according to the method developed by Stanković et al. (27). The chromatography system used was a 1200 series diode array and multiple wavelength detector (Agilent Technologies, USA), with Zorbax Eclipse Plus C8 ( $3 \times 150 \mathrm{~mm} ; 3.5 \mu \mathrm{m})$ as the column. The mobile phase was a 20:80 v/v mixture of acetonitrile and phosphate buffer $(\mathrm{pH} 2.5)$; flow rate was set at $0.8 \mathrm{~cm}^{3} / \mathrm{min}$, column temperature was $40^{\circ} \mathrm{C}$, and the detection wavelength was $210 \mathrm{~nm}$. The injected sample volume was $0.01 \mathrm{~cm}^{3}$.

\section{Dissolution Test}

The dissolution test was performed with a DT 126 light dissolution tester (ERWEKA GmbH, Germany). A paddle apparatus (USP apparatus 2) with six glass vessels was used. The rotation speed was set to $50 \mathrm{rpm}$ and the temperature of dissolution medium was $37^{\circ} \mathrm{C}$. As the dissolution medium, $900 \mathrm{~mL}$ of vaginal fluid simulant was used; the composition is given in Table $2(28,29)$. The test lasted for 30 minutes, and the samples were taken from the vessel every 5 minutes (at intervals of 5,10 , $15,20,25$, and $30 \mathrm{~min})$. Sampling was carried out from a position halfway between the surface of the dissolution medium and the top of the paddle. The volume reduction of the dissolution medium, resulting from sampling, was calculated afterwards. The test samples were filtered and then underwent HPLC analysis.

The percentage of clindamycin phosphate released at each time interval was calculated using the calibration curve.

Table 2. Composition of Vaginal Fluid Simulant $(1000 \mathrm{~mL}, \mathrm{pH}=$ 4.2) (29)

\begin{tabular}{|c|c|}
\hline Substance & Content (g) \\
\hline $\mathrm{NaCl}$ & 3.51 \\
\hline $\mathrm{KOH}$ & 1.4 \\
\hline $\mathrm{Ca}(\mathrm{OH})_{2}$ & 0.22 \\
\hline Albumin & 0.015 \\
\hline Lactic acid & 2.0 \\
\hline Acetic acid & 1.0 \\
\hline Glycerol & 0.16 \\
\hline Urea & 0.4 \\
\hline Glucose & 5.0 \\
\hline Distilled water & up to 1000 \\
\hline
\end{tabular}

\section{Comparison of Dissolution Profiles}

The most widely accepted method that allows for comparing the dissolution rate profiles is based on the calculation of the difference factor $\left(f_{1}\right)$ and similarity factor $\left(f_{2}\right)(30)$. The tested profiles can be considered similar if $0<f_{1}<15$ and/or if $50<f_{2}<100$ (31).

\section{RESULTS AND DISCUSSION Uniformity of Mass}

The mass of each measured pessary is presented in Table 
3. According to $E P$, not more than two pessaries may have mass that deviates from the average mass more than $5 \%$ (3). In this study, the deviation limits for pessaries with $4 \%$, $5 \%$, and $6 \%$ of polysorbate 80 were $2.57-2.84,2.64-2.91$, and 2.67-2.95, respectively. As it can be seen in Table 3, none of our compounded pessaries exceeded the limits prescribed by the $E P$, indicating that all tested pessaries were produced in accordance with the requirements of $E P$.

Table 3. Mass (g) Variation for Tested Pessaries ( $A, B$, and $C)$

\begin{tabular}{|c|c|c|c|c|c|c|}
\hline & \multicolumn{2}{|c|}{ A (4\% Tween 80) } & \multicolumn{2}{c|}{ B (5\% Tween 80) } & \multicolumn{2}{c|}{ C (6\% Tween 80) } \\
\hline \multirow{4}{*}{$\begin{array}{c}\text { Individual } \\
\text { Values }\end{array}$} & 2.68 & 2.71 & 2.74 & 2.76 & 2.80 & 2.81 \\
\cline { 2 - 7 } & 2.71 & 2.69 & 2.79 & 2.78 & 2.76 & 2.77 \\
\cline { 2 - 7 } & 2.73 & 2.72 & 2.75 & 2.82 & 2.79 & 2.84 \\
\cline { 2 - 7 } & 2.72 & 2.73 & 2.81 & 2.76 & 2.85 & 2.80 \\
\cline { 2 - 7 } & 2.67 & 2.69 & 2.77 & 2.74 & 2.80 & 2.82 \\
\cline { 2 - 7 } & 2.75 & 2.71 & 2.77 & 2.74 & 2.80 & 2.80 \\
\cline { 2 - 7 } & 2.67 & 2.68 & 2.81 & 2.79 & 2.81 & 2.80 \\
\cline { 2 - 7 } & 2.71 & 2.73 & 2.78 & 2.78 & 2.85 & 2.83 \\
\cline { 2 - 7 } & 2.68 & 2.61 & 2.77 & 2.81 & 2.82 & 2.80 \\
\cline { 2 - 7 } & 2.73 & 2.72 & 2.74 & 2.80 & 2.79 & 2.77 \\
\hline $\begin{array}{c}\text { Average } \pm \\
\text { SD (g) }\end{array}$ & $2.70 \pm 0.03$ & $2.78 \pm 0.03$ & $2.81 \pm 0.02$ \\
\hline $\begin{array}{c}\text { Average }+ \\
5 \% \text { (g) }\end{array}$ & 2.84 & \multicolumn{2}{|c}{2.91} & \multicolumn{2}{|c}{2.95} \\
\hline $\begin{array}{c}\text { Average - } \\
5 \% \text { (g) }\end{array}$ & 2.57 & \multicolumn{2}{|c}{2.64} & \multicolumn{2}{|c}{2.67} \\
\hline
\end{tabular}

SD: standard deviation.

\section{Uniformity of Content}

The content of clindamycin phosphate in the tested pessaries was calculated from the constructed calibration curve (Fig. 1). Table 4 shows the clindamycin phosphate content in 10 randomly selected tested pessaries in each group (A, B, C). The results showed that all tested pessaries were in consonance with the requirements of EP because they were within $85-115 \%$ of the average content (3).

\section{Dissolution Test}

Extemporaneous compounding is unfortunately not performed in all pharmacies due to highly developed industrial production, but still remains an important skill of pharmacists in times of drug shortage or in case of need for personalized therapy formulated for a particular patient (32). In the Republic of Serbia, Compounding Formulae 2008 is a book that provides a protocol for many different types of preparations, including suppositories and pessaries (33). Extemporaneous compounds are not subject to quality control or analysis of drug stability and efficacy (34). Therefore, some methods need to be evaluated for potential use in the analysis of extemporaneous preparations. One method could be a dissolution test, a significant tool in the process of drug development and drug quality control. Initially, this test was established for solid dosage forms, but was later extended to a variety of other dosage forms (suspensions, transdermal patches, semisolid topical preparations, liposomes, suppositories, etc.) (35).

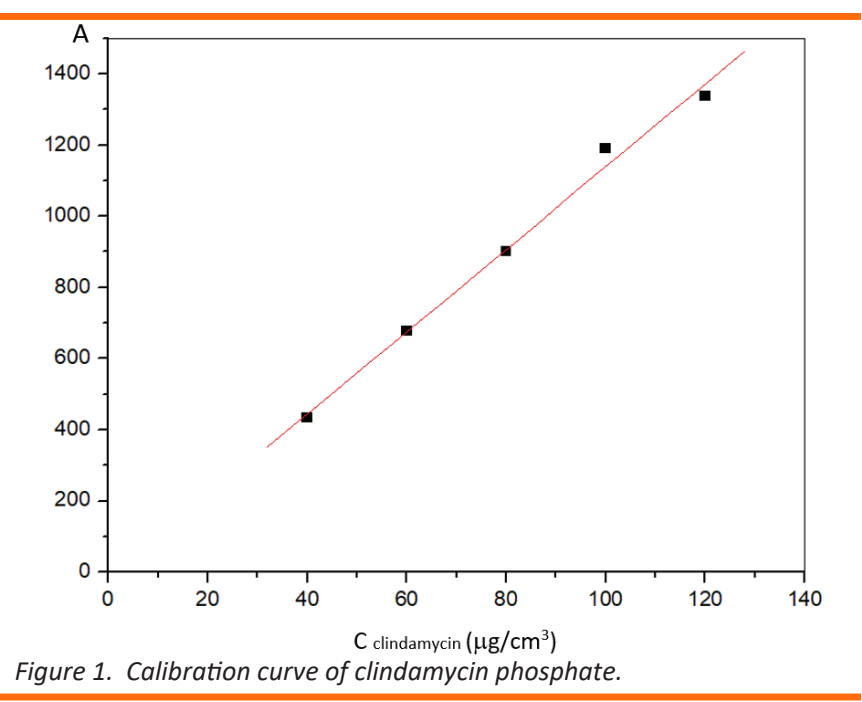

Table 4. Mass (mg) of Clindamycin Phosphate in Pessaries A, B and $C$

\begin{tabular}{|c|c|c|c|c|c|c|}
\hline & \multicolumn{2}{|c|}{ A (4\% Tween 80) } & \multicolumn{2}{c|}{ B (5\% Tween 80) } & \multicolumn{2}{c|}{ C (6\% Tween 80) } \\
\hline \multirow{4}{*}{$\begin{array}{c}\text { Individual } \\
\text { Values }\end{array}$} & 114.02 & 120.6 & 112.05 & 123.0 & 121.6 & 123.0 \\
\cline { 2 - 7 } & 113.0 & 106.0 & 118.0 & 115.7 & 119.0 & 122.4 \\
\cline { 2 - 7 } & 107.0 & 124.3 & 120.1 & 117.3 & 118.2 & 115.4 \\
\cline { 2 - 7 } & 109.5 & 112.2 & 119.4 & 108.3 & 115.6 & 121.2 \\
\cline { 2 - 7 } & 125.05 & 115.5 & 121.0 & 124.2 & 117.9 & 120.9 \\
\hline $\begin{array}{c}\text { Average } \pm \text { SD } \\
\text { (mg) }\end{array}$ & $114.72 \pm 6.72$ & \multicolumn{2}{|c|}{$117.91 \pm 4.88$} & $119.52 \pm 2.72$ \\
\hline $\begin{array}{c}\text { Average + } \\
15 \% \text { (mg) }\end{array}$ & \multicolumn{2}{|c|}{131.92} & \multicolumn{2}{|c|}{135.59} & \multicolumn{2}{c|}{137.45} \\
\hline $\begin{array}{c}\text { Average - } \\
15 \% \text { (mg) }\end{array}$ & \multicolumn{2}{|c|}{97.51} & \multicolumn{2}{|c|}{100.22} & \multicolumn{2}{c|}{101.59} \\
\hline
\end{tabular}

SD: standard deviation.

Suppositories are an example of a frequently made extemporaneous preparation. Pessaries tested in the current study are made with glycerol-gelatin base, with the addition of polysorbate 80 as a surfactant. Since the glycerol-gelatin base is hydrophilic and dissolves in body (vaginal) fluid, a paddle apparatus can be used to determine the dissolution profile of the active substance in these pessaries (35).

Nonionic surfactants can help deliver the active substance from a dosage form. In another study, macrogol-based 
suppositories with polysorbate 80 showed higher content of active substance compared to suppositories without the surfactant (36). Ranjita and Kamalinder showed that surfactants can increase the release of active substance from suppositories. They tested different surfactants and showed that nonionic surfactants, such as Labrasol (mixture of mono-, di- and triglycerides and mono- and di- fatty acid esters of polyethylene glycol (PEG)-8 and free PEG-8, with caprylic and capric acid), lecithin and sorbitan monooleate, and anionic surfactant sodium lauryl sulfate increased the drug dissolution rate (37).

Dissolution profiles of the tested pessaries are shown in Figure 2. There was little difference between the percentages of dissolved clindamycin phosphate from different groups of pessaries. However, the highest percentage of active substance was dissolved from pessaries with the lowest percentage of surfactant, and the lowest percentage of drug was dissolved from pessaries with the most surfactant (Fig. 2). Similar results were observed in one study where dioctyl sulfosuccinate sodium, an anionic surfactant, increased the dissolution rate of the active substance from the suppository; however, the increase in its concentration caused a slower release of the active substance (37). Therefore, it could be said that a surfactant can help release the active substance from the suppositories, but only if they are used in a certain concentration.

Values of $f_{1}$ lower than 15 (0-15) and values of $f_{2}$ greater than 50 (50-100) ensure the identity or bioequivalence of the dissolution curves. All examined groups of pessaries had a similar dissolution profile, i.e., calculated values of $f_{1}$ were lower than 15 ( $\mathrm{A}$ vs $\mathrm{B}=9$; $\mathrm{A}$ vs $\mathrm{C}=10$; $\mathrm{B}$ vs $\mathrm{A}=10$; $B$ vs $C=1 ; C$ vs $A=11 ; C$ vs $B=1$ ) and $f_{2}$ values were higher than 50 ( $A$ vs $B=55 ; B$ vs $C=67$; $A$ vs $C=51$ ).

Further studies on a wider range of surfactant concentrations should be performed. Also, more surfactants should be included in the research.

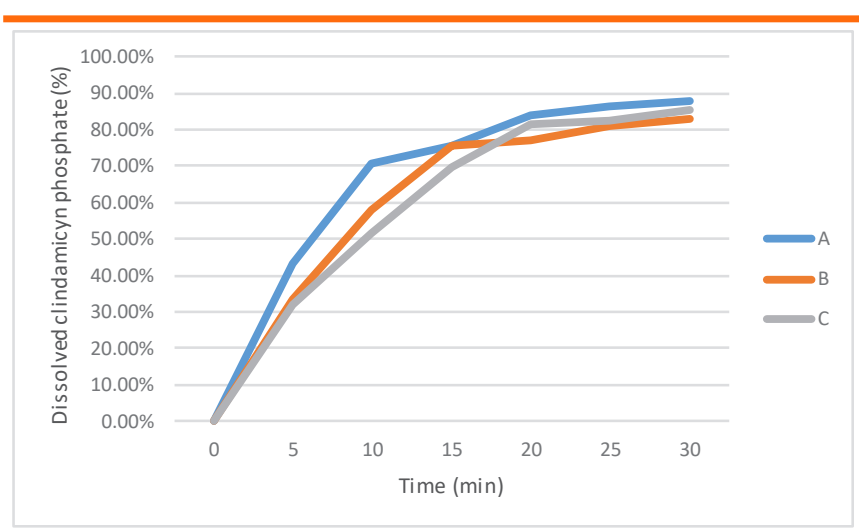

Figure 2. Dissolution profiles of the tested pessaries $(A, B$, and $C)$.

\section{CONCLUSION}

Extemporaneously compounded pessaries are made when personalized therapy is needed or when there is a deficit of drugs in the market. However, these preparations are not subject to control and appropriate methods should be evaluated for their analysis. In the current study, a dissolution test was performed as a method of analyzing the release rate of three groups of pessaries with clindamycin phosphate as the active substance and with different concentrations of polysorbate 80 as a surfactant incorporated into the glycerol-gelatin base. Although all groups showed similar dissolution profiles and were bioequivalent, there were slight differences between percentages of dissolved active substance depending on the surfactant concentration.

\section{FUNDING}

This work was supported by the Republic of Serbia, Ministry of Education, Science and Technological Development, program for financing scientific research work (no. 451-03-68/2020-14/200133).

\section{CONFLICT OF INTEREST}

The authors disclosed no conflicts of interest related to this article.

\section{REFERENCES}

1. Melnik, G. M.; Yarnykh, T. G.; Rukhmakova, O. A. Pharmacopaine aspects of extemporaneous technology of soft medicines and suppositories. J. Adv. Pharm. Educ. Res. 2020, 10, 60-65.

2. Nahata, M. C.; Allen, L. V., Jr. Extemporaneous drug formulations. Clin. Ther. 2008, 30, 2112-2119. DOI: 10.1016/j. clinthera.2008.11.020.

3. European Pharmacopoeia, 9th ed; European Directorate for the Quality of Medicines \& Healthcare, Council of Europe: Strasbourg, France, 2017.

4. das Neves, J.; Bahia, M. F. Gels as vaginal drug delivery systems. Int. J. Pharm. 2006, 318, 1-14. DOI: 10.1016/j.ijpharm.2006.03.012

5. IPEC Federation website. IPEC Federation. https://ipecfederation.org (accessed January 1, 2021).

6. Đurić, Z. [Pharmaceutical biotechnology and biopharmacy Part I] [in Serbian].. Nijansa: Zemun, 2004.

7. Yugoslav Pharmacopoeia 2000. Federal Institute for Health Protection and Promotion, Modern Administration, Beograd, 2000.

8. Mehta, A. C. Dissolution testing of tablet and capsule dosage forms. J. Clin. Pharm. Ther. 1993, 18, 415-420. DOI: 10.1111/ j.1365-2710.1993.tb00880.x

9. Uddin, R.; Saffoon, N.; Sutradhar, K. B. Dissolution and dissolution apparatus: a review. Int. J. Cur. Biomed. Phar. Res. 2011, 1, 201207.

10. Galia, E.; Nicolaides, E.; Hörter, D.; Löbenberg, R.; Reppas, C.; Dressman, J. B. Evaluation of various dissolution media for 
predicting in vivo performance of class I and II drugs. Pharm. Res. 1998, 15, 698-705. DOI: 10.1023/A:1011910801212.

11. Takeuchi, S.; Tsume, Y.; Amidon, G. E.; Amidon, G. L. Evaluation of a three compartment in vitro gastrointestinal simulator dissolution apparatus to predict in vivo dissolution. J. Pharm. Sci. 2014, 103, 3416-3422. DOI: 10.1002/jps.24112.

12. Bai, G.; Armenante, P. M.; Plank, R. V.; Gentzler, M.; Ford, K.; Harmon, P. Hydrodynamic investigation of USP dissolution test apparatus II. J. Pharm. Sci. 2007, 96, 2327-2349. DOI: 10.1002/ jps.20818.

13. Vermani, K.; Garg, S. The scope and potential of vaginal drug delivery. Pharm. Sci. Technol. Today 2000, 3, 359-364. DOI: 10.1016/s1461-5347(00)00296-0.

14. Georgijević, A., Cjukić-Ivancević, S., Bujko, M. [Bacterial vaginosis. Epidemiology and risk factors] [in Serbian]. Srp. Arh. Celok. Lek. 2000, 128, 29-33.

15. Bacterial vaginosis (BV). Centers for Disease Control and Prevention website. U.S. Department of Health \& Human Services. https://www.cdc.gov/std/bv/stats.htm (accessed January 1, 2021).

16. Koumans, E. H.; Sternberg, M.; Bruce, C.; McQuillan, G.; Kendrick, J.; Sutton, M.; Markowitz, L. E. The prevalence of bacterial vaginosis in the United States, 2001-2004; associations with symptoms, sexual behaviors, and reproductive health. Sex. Transm. Dis. 2007, 34, 864-869. DOI: 10.1097/ OLQ.0b013e318074e565.

17. Verstraelen, H.; Verhelst, R. Bacterial vaginosis: an update on diagnosis and treatment. Expert Rev. Anti Infect. Ther. 2009, 7, 1109-1124. DOI: 10.1586/eri.09.87.

18. Greaves, W. L.; Chungafung, J.; Morris, B.; Haile, A.; Townsend, J. L. Clindamycin versus metronidazole in the treatment of bacterial vaginosis. Obstet. Gynecol. 1988, 72, 799-802.

19. Sweetman, C. S. Martindale: The Complete Drug Reference, 36th ed.; The Pharmaceutical Press: London, 2009.

20. Kasten, M. J. Clindamycin, metronidazole, and chloramphenicol. Mayo. Clin. Proc. 1999, 74, 825-833. DOI: 10.4065/74.8.825.

21. Mason, D. J.; Dietz, A.; DeBoer, C. Lincomycin. a new antibiotic. I. Discovery and biological properties. Antimicrob. Agents Chemother. 1962, 1963, 554-559.

22. Lewis, C.; Clapp, H. W.; Grady, J. E. In vitro and in vivo evaluation of lincomycin, a new antibiotic. Antimicrob. Agents. Chemother.1962, 1963, 570-582.

23. McGehee,R. F. Jr.;Smith, C. B.; Wilcox, C.; Finland. M. Comparative studies of antibacterial activity in vitro and absorption and excretion of lincomycin and clinimycin. Am. J. Med. Sci. 1968, 256, 279-292. DOI: 10.1097/00000441-196811000-00002.

24. Sande, M. A.; Mandell, G. L. Antimicrobial agents; tetracyclines, chloramphenicol, erythromycin, and miscellaneous antibacterial agents. In Goodman and Gilman's The Pharmacological Basis of Therapeutics, 7th ed.; Gilman, A. G., Goodman, L. S., Rail, T. W., Murad, F., Eds; Macmillan: New York, 1985; pp 1179-1191.

25. Chang, F. N.; Sih, C. J.; Weisblum, B. Lincomycin, an inhibitor of aminoacyl sRNA binding to ribosomes. Proc. Natl. Acad. Sci. USA.
1966, 55, 431-438. DOI: 10.1073/pnas.55.2.431

26. Savić, V. Lj.; Sunarić, S. M.; Živković, J. V.; Stamenković, A. S.; Nikolić, I. Lj.; Tačić, A. D.; Nikolić, V. D. Determination of clindamycin phosphate in extemporaneously prepared pessaries with glycerol-gelatin basis. Adv. Technol. 2019, 8, 66-71. DOI: 10.5937/savteh1902066S.

27. Stanković, M.; Savić, V.; Marinković, V. Determination of clindamycin phosphate in different vaginal gel formulations by reverse phase high performance liquid chromatography. Acta Faculatis Medicae Naissensis. 2013, 30, 63-71. DOI: 10.2478/ v10283-012-0038-y

28. Jug, M.; Hafner, A.; Lovrić, J.; Kregar, M. L.; Pepić, I.; Vanić, Ž.; Cetina-Čižmek, B.; Filipović-Grčić, J. In vitro dissolution/release methods for mucosal delivery systems. ADMET DMPK. 2017, 5, 173-182. DOI: 10.5599/admet.5.3.425.

29. Owen, D. H.; Katz, D. F. A vaginal fluid simulant. Contraception. 1999, 59, 91-95. DOI: 10.1016/S0010-7824(99)00010-4

30. Moore, J. W.; Flanner, H. H. Mathematical comparison of curves with an emphasis on in vitro dissolution profiles. Pharm. Technol. 1996, 20, 64-74.

31. Dissoluton Testing of Immediate Release Solid Oral Dosage Forms; Guidance for Industry; U.S. Department of Health \& Human Services, Food and Drug Administraton, Center for Drug Evaluaton and Research (CDER), U.S. Government Printng Offce: Washington, DC, 1997.

32. Allen, L. V. Suppositories as drug delivery systems. J. Pharm. Care Pain Symptom Control 1997, 5, 17-26. DOI: 10.1300/ J088v05n02_03.

33. Vuleta, G.; Milić. J. [Magistral formulas: MF 2008] [in Serbian]. Pharmaceutical Society of Serbia: Beograd, 2008.

34. Falconer, J. R.; Steadman, K. J. Extemporaneously compounded medicines. Aust. Prescr. 2017, 40, 5-8. DOI: 10.18773/ austprescr.2017.001.

35. Siewert, M.; Dressman, J.; Brown, C. K.; Shah, V. P.; Aiache, J. M.; Aoyagi, N.; Bashaw, D.; Brown, C.; Brown, W.; Burgess, D.; Crison, J.; DeLuca, P.; Djerki, R.; Dressman, J.; Foster, T.; Gjellan, K.; Gray, V.; Hussain, A.; Ingallinera, T.; Klancke, J.; Kraemer, J.; Kristensen, H.; Kumi, K.; Leuner, C.; Limberg, J.; Loos, P.; Margulis, L.; Marroum, P.; Moeller, H.; Mueller, B.; Mueller-Zsigmondy, M.; Okafo, N.; Ouderkirk, L.; Parsi, S.; Qureshi, S.; Robinson, J.; Shah, V.; Siewert, M.; Uppoor, R.; Williams, R. FIP/AAPS guidelines to dissolution/in vitro release testing of novel/special dosage forms. AAPS PharmSciTech. 2003, 4, 43-52. DOI: 10.1208/ pt040107.

36. Savić, V.; Sunarić, S.; Živković, J.; Martinović, M.; Nešić, I.; Gajić, I. The influence of surfactants on the content of clindamycin phosphate in macrogol based compounded vagitories. Macedonian Pharm. Bull. 2020, 66, 225-226. DOI: 10.33320/ maced.pharm.bull.2020.66.03.112

37. Ranjita, S. H.; Kamalinder, S. I. In-vitro release of paracetamol from suppocire suppositories: role of additives. Malays. J. Pharm. Sci. 2010, 8, 57-71.

Dissolution 